\title{
Termografia infravermelho na estimativa de conforto térmico de frangos de corte
}

\author{
Guilherme R. do Nascimento ${ }^{1}$, Irenilza A. Nääs ${ }^{2}$, Marta S. Baracho ${ }^{3}$, Danilo F. Pereira ${ }^{4} \&$ Diego P. Neves ${ }^{5}$ \\ ${ }^{1}$ UEM. Maringá, PR. E-mail: nascimentogr@gmail.com (Autor correspondente) \\ ${ }^{2}$ FEAGRI/UNICAMP. Campinas, SP. E-mail: irenilza@gmail.com \\ ${ }^{3}$ FEAGRI/UNICAMP. Campinas, SP. E-mail: martbaracho@yahoo.com.br \\ ${ }^{4}$ UNESP. Tupã, SP. E-mail: danilo@tupa.unesp.br \\ ${ }^{5}$ FEAGRI/UNICAMP. Campinas, SP. E-mail: diegopneves@gmail.com
}

\section{Palavras-chave:}

bem-estar

temperatura superficial

termorregulação

\section{R E S U M O}

As instalações avícolas devem assegurar um ambiente de conforto térmico que proporcione ao animal expressar todo o seu potencial genético para produção motivo pelo qual novas ferramentas estão sendo aplicadas para medir o conforto térmico animal destacando-se as câmeras termográficas. Neste trabalho objetivou-se avaliar a associação da temperatura superficial das aves com as das instalações e estimar a transferência de calor sensível. Para isto foram registradas as condições térmicas de alojamento em dois aviários com sistemas de ventilação distintos, no período de março a abril de 2011. Os aviários foram divididos em seis quadrantes para a coleta das temperaturas superficiais obtidas através de uma câmera termográfica infravermelho. Em cada quadrante também foram registradas temperatura ambiente, umidade relativa e velocidade do ar durante as coletas das imagens. Constatou-se que as temperaturas superficiais das aves estão associadas à temperatura superficial da instalação (cortinas laterais, forro e cama). No aviário com ventilação negativa foram registradas maiores velocidades do ar em relação ao convencional razão pela qual possibilitou a maior transferência de calor sensível pelas aves, sugerindo melhores condições de conforto térmico.
Key words:

welfare

surface temperature

thermoregulation

\section{Infrared thermography in the estimation of thermal comfort of broilers}

\begin{abstract}
A B S T R A C T
Poultry facilities must provide an environment that ensures thermal comfort allowing the animal to express its genetic potential for production; and new tools are being applied to measure the thermal comfort, especially thermal cameras. The objective of this study was to evaluate the association of the surface temperature of the birds with those from the facilities, and estimate the sensible heat transfer. For this, the thermal conditions of rearing in two aviaries with different ventilation systems, during the period of March to April 2011 were recorded. The aviaries were divided into six quadrants for the registration of surface temperatures obtained using an infrared thermal camera. In each quadrant the ambient temperature, relative humidity and wind velocity during the obtention of images were also recorded. It was observed that the surface temperatures of birds are associated with the surface temperature of the rearing facilities (side curtains, roof and litter). In aviary with negative pressure higher wind speeds compared to the conventional one were recorded and; therefore, allowed a higher sensible heat transfer by birds, suggesting that this provided better conditions for thermal comfort.
\end{abstract}

\section{INTRODUÇÃo}

Para manter a competitividade da produção avícola brasileira é imprescindível aperfeiçoar os abrigos e o manejo para superar os efeitos prejudiciais dos fatores ambientais críticos, como altas temperaturas e umidade relativa do ar. As instalações devem assegurar a manutenção da homeotermia para manter o conforto térmico animal e garantir o bem-estar na produção com o mínimo gasto de energia (Aerts et al., 2003; Welker et al., 2008; Santos et al., 2009).

São dois, basicamente, os tipos de sistemas de ventilação utilizados na avicultura brasileira: sistemas de ventilação por pressão negativa, nos quais o ar é succionado por exaustores acarretando em vácuo parcial no interior do aviário, e o sistema de ventilação de pressão positiva cujo ar é forçado para dentro da instalação ocasionando aumento da pressão interna da instalação. Em ambos os sistemas o gradiente de pressão interno-externo gerado acarreta no deslocamento do ar interno para fora do aviário (Santos et al., 2009).

Uma definição adequada da zona de conforto térmico pode ser indicada como sendo a faixa de temperatura ambiente em que a taxa metabólica é mínima e a homeotermia é mantida com menor gasto energético. A capacidade das aves dissiparem calor 
diminui na medida em que a temperatura ambiente e a umidade relativa se elevam acima da zona termoneutra (temperatura do ar, Ta, $\sim 24^{\circ} \mathrm{C}$ e umidade relativa do ar, UR $\sim 70 \%$ ); como resultado, a temperatura corporal da ave sobe e logo aparecem os sintomas do estresse calórico (Yahav et al., 2005; Curto et al., 2007).

A análise termográfica surgiu como técnica de mapeamento da temperatura superficial das aves, principalmente por ser uma forma de medição não invasiva, propiciando também a estimativa de perda de calor (Nascimento et al., 2011). A técnica tem grande importância no cálculo das transferências de calor e de massa entre as aves e o ambiente ao seu redor para o dimensionamento de sistemas de ventilação e resfriamento evaporativo, tal como a inferência sobre o manejo das aves (Aerts et al., 2003; Yahav et al., 2004).

O objetivo deste trabalho foi avaliar o conforto térmico de frangos de corte em dois aviários localizados na mesma região geográfica, com diferentes sistemas de climatização, correlacionando as temperaturas superficiais das aves com as condições climáticas de alojamento e estimar a perda de calor sensível das aves com auxílio da termografia infravermelho.

\section{Material e Métodos}

O experimento foi realizado em uma granja comercial de frangos de corte no município de Rio Claro, localizado no Centro-Leste do estado de São Paulo, nas coordenadas $22^{\circ} 05^{\prime}$ e $22^{\circ} 40^{\prime} \mathrm{S}, 47^{\circ} 30^{\prime}$ e $47^{\circ} 55^{\prime} \mathrm{W}$ e altitude de $613 \mathrm{~m}$, no período de março a abril de 2011.

Foram utilizados dois aviários com sistemas de climatização diferentes, dispostos lado a lado na distância de $30 \mathrm{~m}$ entre si. O aviário, classificado como climatizado, possui sistema de ventilação por pressão negativa e resfriamento adiabático evaporativo; o outro aviário, classificado como convencional, possui ventilação natural associada à ventilação forçada por ventiladores. As instalações foram monitoradas durante os 28 dias de criação de um lote de frangos de corte. Os aviários foram divididos longitudinalmente em três partes, cada uma delas em outras duas perpendiculares, totalizando seis quadrantes com dimensões de 6 x $40 \mathrm{~m}$.

Os dois aviários possuem as mesmas dimensões: $12 \mathrm{~m}$ de largura por $120 \mathrm{~m}$ de comprimento e orientação leste-oeste. Ambos com pé-direito de $3,0 \mathrm{~m}$ e pilares de concreto com espaçamento de $8 \mathrm{~m}$ que sustentavam as tesouras de madeira. A cobertura do aviário climatizado era constituída de cerâmica e do aviário convencional de fibrocimento. A cortina lateral utilizada para vedar o aviário climatizado era azul, tanto a interna quanto a externa. $\mathrm{O}$ forro interno utilizado como isolante térmico em ambos os aviários era amarelo. Cortinas e forros eram constituídos de polipropileno não laminado com espessura de 0,17 $\mathrm{mm}$ e a emissividade adotada foi de 0,97 (He \& Hoyano, 2009). Em ambos os aviários a cama de frango era constituída de oito $\mathrm{cm}$ de maravalha misturada com palha de arroz.

Para o monitoramento das variáveis ambientais foi instalado, no centro de cada quadrante, um data logger Hobo H8 Onset ${ }^{\circ}$ para o registro da temperatura do ar $(\mathrm{Ta})$ e da umidade relativa (UR) a cada 15 min. Um anemômetro modelo HTA 4200 Kestrel $^{\circ}$ foi utilizado para registrar a velocidade do ar (VA) no centro de cada quadrante a $50 \mathrm{~cm}$ do piso no momento do registro das imagens termográficas.

Para o registro das temperaturas de superfícies foram capturadas fotos termográficas às $12 \mathrm{~h} 00$ ao final de cada semana $(7,14,21$ e 28 dias) utilizando-se uma câmera termográfica infravermelho TESTO'. As imagens foram coletadas a partir do centro de cada quadrante das seguintes partes: da (i) cama de frango; (ii) do forro; (iii) da cortina lateral e (iv) das aves. Com base nessas imagens, calculou-se a Temperatura Superficial Média das Aves (TSMA) com o auxílio do software IRSOFT", selecionando-se 30 pontos na área da imagem para o cálculo da temperatura média dessas seleções (Nascimento et al., 2011).

Para comparar as condições térmicas internas nos aviários foram utilizadas as fotos termográficas panorâmicas (Figura $1 \mathrm{~A} \mathrm{e} 1 \mathrm{~B}$ ) as quais foram registradas semanalmente e no mesmo momento nos dois aviários. O histograma da temperatura superficial das aves nas fotos panorâmicas (TSAP) foi gerado e selecionadas as médias das temperaturas das aves de 10 imagens termográficas por aviário por dia de registro.

As perdas de calor sensível por radiação $\left(Q_{R}\right)$ e por convecção $\left(\mathrm{Q}_{\mathrm{C}}\right)$ nos dois aviários foram calculadas utilizando-

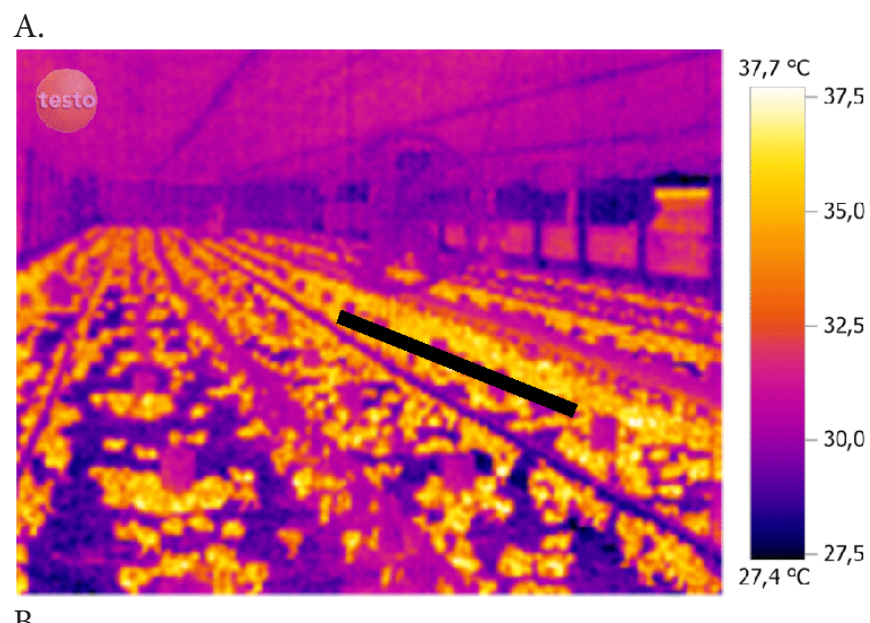

B.

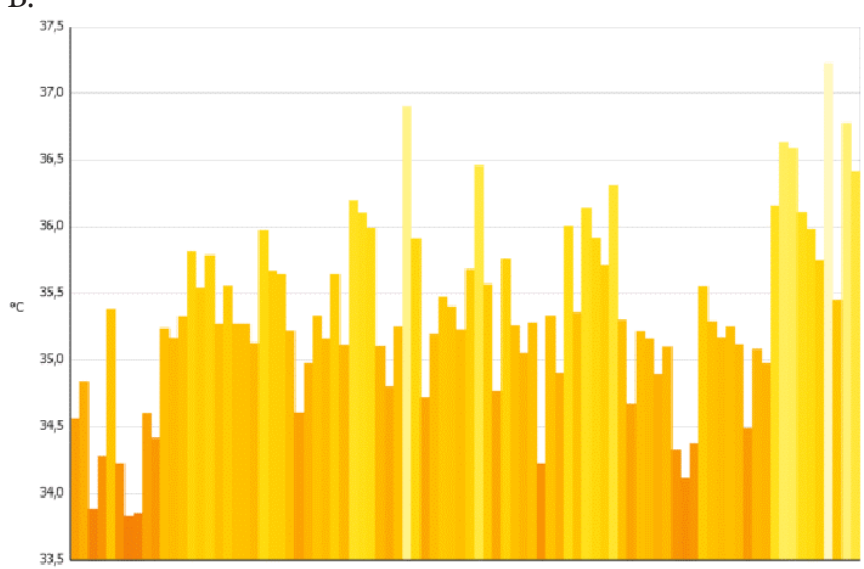

Figura 1. Imagem termográfica do interior de um aviário (A) e o histograma do perfil térmico das aves (B) selecionadas na reta indicada em (A) 
se o conjunto de equações, proposto por Yahav et al. (2004) e Brecht et al. (2005), Eqs. 1, 2, 3 e 4.

$$
\begin{gathered}
\mathrm{Q}_{\mathrm{R}}=\mathrm{e} \cdot \sigma \cdot \mathrm{A} \cdot\left(\mathrm{T}_{\mathrm{S}}^{4}-\mathrm{T}_{\mathrm{ar}}^{4}\right) \\
\mathrm{Q}_{\mathrm{C}}=\mathrm{h} \cdot \mathrm{A} \cdot\left(\mathrm{T}_{\mathrm{s}}-\mathrm{T}_{\mathrm{ar}}\right) \\
\mathrm{Q}=\mathrm{Q}_{\mathrm{R}}+\mathrm{Q}_{\mathrm{C}} \\
\mathrm{h}=0,336 \cdot 4,184 \cdot\left(1,46+\sqrt{\mathrm{V}_{\mathrm{AR}} \cdot 100}\right)
\end{gathered}
$$

em que:

$$
\begin{array}{ll}
\mathrm{Q} & \text { - calor total, }\left(\mathrm{W} \mathrm{m}^{-2}\right)^{-1} \\
\mathrm{e} & \text { - emissividade }(0,95) \\
\sigma & \text { - constante de Stefan-Boltzman, 5,6691 } \times 10^{-8} \\
\mathrm{~A} & \text { - área da superfície da ave, } \mathrm{m} \\
\mathrm{h} & \text { - coeficiente de transferência de calor, }\left(\mathrm{W}\left(\mathrm{m}^{2} \mathrm{~K}\right)^{-1}\right)
\end{array}
$$

A área superficial da ave ( $\left.A_{\mathrm{s}}\right)$ foi estimada através da Eq. 5, proposta por Silva et al. (2009):

$$
\mathrm{A}_{\mathrm{S}}=3,86 \mathrm{Mc}^{0,74}
$$

em que $\mathrm{Mc}$ corresponde à massa corporal ( $\mathrm{g}$ ). A massa corporal média das aves foi mensurada a partir da pesagem de 10 aves por quadrante com idades de 7, 14, 21 e 28 dias, totalizando 60 aves por aviário.

Foram realizados a análise de variância (ANOVA) e o teste F, seguidos de testes de médias de Tukey com 0,05 de significância para verificar diferenças entre os quadrantes dentro dos aviários. Teste de t-Student para comparações entre os dois aviários com grau de confiança de $95 \%$, quando a variável apresentava distribuição normal. O teste não paramétrico de Kruskal-Wallis com $95 \%$ de confiança foi utilizado para as variáveis que não apresentaram distribuição normal. A análise multivariada de componentes principais foi utilizada para gerar gráficos de associação das temperaturas superficiais com variáveis ambientais nos aviários com sistemas de ventilação distintos. As análises estatísticas foram feitas com auxílio do software Minitab $15^{\circ}$ (Minitab Inc., Pennsylvania, USA).

\section{Resultados e Discussão}

Os valores médios de temperatura $(\mathrm{Ta})$ e umidade do ar (UR) no interior dos aviários em função da idade das aves, comparados pelo teste de t-Student, estão apresentados na Tabela 1.

Não houve diferença $(p>0,05)$ da temperatura e da umidade relativa do ar, entre os sistemas de climatização nos dois aviários analisados pelo teste $\mathrm{t}$-Student (Tabela 1). As temperaturas na primeira semana com sete dias de idade são reflexos da fase de aquecimento; a partir da segunda semana a temperatura do ar variou de 25,9 a $26,1^{\circ} \mathrm{C}$ não havendo condições de estresse térmico para as aves na fase de crescimento, nos dois aviários, conforme limites de termoneutralidade recomendados por
Tabela 1. Comparação das médias de temperatura (Ta) e umidade relativa (UR) do ar nos dois aviários nas quatro idades das aves de monitoramento

\begin{tabular}{cccccc}
\hline \multirow{2}{*}{ Idade } & \multicolumn{2}{c}{ Ta $\left({ }^{\circ} \mathbf{C}\right)$} & & \multicolumn{2}{c}{ UR (\%) } \\
\cline { 2 - 3 } \cline { 5 - 6 } & Climatizado & Convencional & & Climatizado & Convencional \\
7 & $27,7 \pm 2,0$ & $28,2 \pm 1,5$ & & $53,4 \pm 9,1$ & $49,2 \pm 6,2$ \\
14 & $26,1 \pm 1,6$ & $25,9 \pm 1,6$ & & $62,2 \pm 6,9$ & $61,0 \pm 5,3$ \\
21 & $26,4 \pm 1,5$ & $26,1 \pm 1,3$ & & $63,7 \pm 9,4$ & $63,2 \pm 6,8$ \\
28 & $25,6 \pm 1,5$ & $25,5 \pm 1,2$ & & $69,7 \pm 6,5$ & $68,2 \pm 3,6$ \\
Média & $26,4 \pm 1,8$ & $26,3 \pm 1,7$ & & $62,4 \pm 9,5$ & $60,9 \pm 8,3$ \\
\hline *t-Student a 0,05 de probabilidade & & &
\end{tabular}

Tinôco (2004) e Menegali et al. (2009). A umidade relativa variou entre a faixa ideal de 50 a 70\% (Santos et al., 2009) nos dois sistemas de ventilação, os dois aviários com diferentes tecnologias de ventilação proporcionaram ambiente de conforto térmico para as aves no período avaliado.

Observou-se efeito $(\mathrm{p}<0,05)$ na temperatura e na umidade do ar entre os quadrantes nos dois sistemas de ventilação. Os quadrantes 5 e 6, localizados na face oeste da instalação, apresentaram as maiores $(\mathrm{p}<0,05)$ temperaturas do ar em ambos os aviários avaliados, provocadas pela incidência dos raios solares na região devido às extensões dos galpões de produção de frangos de corte podendo haver formação de microclimas passíveis de gerar condições inadequadas de conforto térmico. Os quadrantes 1 e 2, localizados na face leste, apresentaram a menor $(\mathrm{p}<0,05)$ temperatura do ar enquanto a parte central dos aviários apresenta temperatura intermediária entre as extremidades (Tabela 2).

A temperatura superficial média das aves (TSMA), temperatura de superfícies do forro e a temperatura de superfície da cama de frango, foram comparadas entre os dois aviários pelo teste não paramétrico de Kruskal-Wallis e gerado gráfico boxplot (Figura 2). Não houve diferença $(p>0,05)$ na TSMA entre os aviários fato que pode ser atribuído à alta correlação entre a temperatura superficial da ave e a temperatura do ar (Nascimento et al., 2011) tendo em vista que a temperatura média do ar não variou nos dois ambientes de criação.

A temperatura superficial da cama de frango não apresentou diferença $(p>0,05)$ entre os aviários; mesmo assim, a temperatura superficial do forro de isolamento interno foi maior $(\mathrm{p}<0,05)$ no aviário climatizado em relação ao convencional, pelo teste de Kruskal-Wallis. Abreu et al.

Tabela 2. Comparação das temperaturas do ar (Ta) e da umidade relativa do ar (UR) entre os quadrantes dentro do aviário climatizado e do aviário convencional

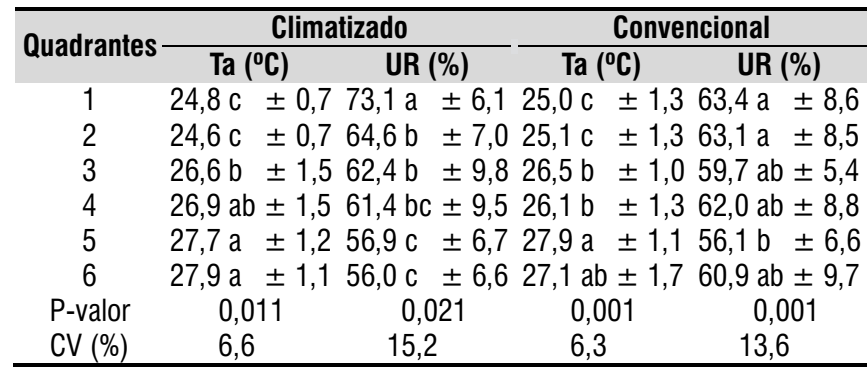

${ }^{a}$ Letras minúsculas diferentes entre os quadrantes indicam diferença significativa pelo teste de Tukey a 0,05 de probabilidade. Ns - não significativo 


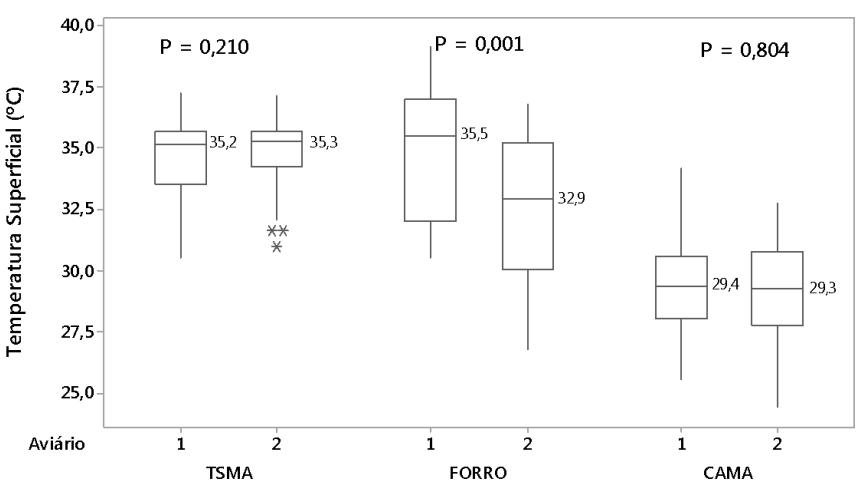

Figura 2. Gráficos boxplot dos dados de temperatura superficial média das aves (TSMA), temperatura superficial do forro (FORRO) e da temperatura superficial da cama de frango (CAMA) entre os aviários climatizado (1) e convencional (2), comparados pelo teste de Kruskal-Wallis

(2007) observaram que o uso de forro resulta em melhores condições de conforto térmico para frangos de corte. A maior temperatura superficial do forro no aviário climatizado pode ser explicada pela telha fibrocimento utilizada como cobertura visto que apresenta maior condutividade térmica comparada com a da telha de cerâmica, proporcionando o aumento da temperatura na parte superior interna do aviário (Fiorelli et al., 2010).

A incidência de raios solares na face norte do aviário aumentou $(\mathrm{p}<0,05)$ as temperaturas superficiais do forro e da cortina lateral nos quadrantes 1,3 e 5 no aviário climatizado (Tabela 3) com exceção do quadrante 6 , na temperatura superficial do forro e do quadrante 4 , na temperatura superficial da cortina lateral, ambos localizados na face sul. Tal resultado ressalta os benefícios de uma boa área de sombreamento ao redor dos galpões corrigindo o microclima com a plantação de árvores ou com a utilização de sombrites.
De acordo com a análise das imagens termográficas panorâmicas, a temperatura superficial média das aves (TSMA) diminuiu com o aumento da idade em ambos os aviários. Em cada idade de observação foram comparadas as TSMA entre os aviários verificando-se que, aos 14 dias, a TSMA foi menor ( $\mathrm{P}$ $<0,05)$ no aviário climatizado $\left(34,1^{\circ} \mathrm{C}\right)$ que no convencional $\left(35,2^{\circ} \mathrm{C}\right)$; aos 14 dias o empenamento nas aves é menor e como o aviário climatizado possui uniformidade de ventilação maior, o ambiente se torna favorável às perdas de calor causando, assim, redução na TSMA.

As variáveis ambientais medidas no momento da coleta das temperaturas superficiais com termografia nos dois aviários demonstraram diferenças significativas entre eles. A umidade relativa foi maior $(\mathrm{P}<0,05)$ pelo teste de t-Student aos sete dias de idade das aves no aviário climatizado em relação ao convencional (Tabela 4); no sistema de ventilação negativa do aviário climatizado a umidade relativa tende a ser maior por ser um sistema fechado. A velocidade do ar apresentou diferença $(\mathrm{P}<0,05)$ em todas as idades de coleta, sendo maior no aviário climatizado em relação ao convencional. O sistema de ventilação negativa do aviário climatizado é mais homogêneo, tornando-se mais eficiente que a ventilação positiva do aviário convencional.

A associação dos dados de termografia infravermelho foi analisada através do gráfico de componentes principais demonstrando que a temperatura superficial média das aves (TSMA) está fortemente associada positivamente com as temperaturas superficiais da instalação (temperaturas superficiais da cortina lateral, do forro e da cama) nos dois sistemas de climatização (Figura 3).

Nos dois sistemas de ventilação a umidade relativa do ar teve baixa correlação com a temperatura superficial média das aves; a temperatura e a velocidade do ar estão fortemente associadas, mas não apresentam associação com a temperatura superficial média das aves (Figura 3).

Tabela 3. Variação da temperatura superficial $\left({ }^{\circ} \mathrm{C}\right)$ por quadrante nos aviários

\begin{tabular}{|c|c|c|c|c|c|c|c|c|}
\hline \multirow{2}{*}{ Quadrante } & \multicolumn{2}{|c|}{ TSMA } & \multicolumn{2}{|c|}{ Cama de frango } & \multicolumn{2}{|c|}{ Forro } & \multicolumn{2}{|c|}{ Cortina lateral } \\
\hline & Clim. & Conv. & Clim. & Conv. & Clim. & Conv. & Clim. & Conv. \\
\hline 1 & $34,5 \pm 0,2$ & $34,8 \pm 0,2$ & $29,4 \pm 0,2$ & $29,5 \pm 1,1$ & $34,6 a b \pm 0,4$ & $32,4 \pm 0,5$ & $30,8 \mathrm{a} \pm 0,3$ & - \\
\hline 2 & $34,6 \pm 0,2$ & $34,7 \pm 0,2$ & $28,9 \pm 0,3$ & $28,6 \pm 0,4$ & $34,2 b \pm 0,5$ & $32,0 \pm 0,5$ & $29,5 b \pm 0,3$ & - \\
\hline 3 & $34,4 \pm 0,2$ & $35,0 \pm 0,2$ & $29,7 \pm 0,3$ & $29,7 \pm 0,3$ & $34,6 a b \pm 0,3$ & $32,5 \pm 0,4$ & $31,5 a \pm 0,3$ & - \\
\hline 4 & $34,7 \pm 0,1$ & $34,8 \pm 0,1$ & $28,8 \pm 0,2$ & $29,3 \pm 0,3$ & $34,0 \mathrm{~b} \pm 0,4$ & $32,2 \pm 0,5$ & $30,7 a b \pm 0,2$ & - \\
\hline 5 & $35,0 \pm 0,2$ & $35,0 \pm 0,1$ & $29,6 \pm 0,2$ & $29,0 \pm 0,2$ & $35,9 a \pm 0,5$ & $33,0 \pm 0,4$ & $32,0 a \pm 0,3$ & - \\
\hline 6 & $34,7 \pm 0,2$ & $35,1 \pm 0,1$ & $29,4 \pm 0,2$ & $29,0 \pm 0,2$ & $34,9 a b \pm 0,5$ & $33,0 \pm 0,5$ & $29,6 b \pm 0,3$ & - \\
\hline P-valor & ns & ns & ns & ns & 0,001 & ns & 0,001 & \\
\hline CV (\%) & 4,2 & 3,4 & 5,5 & 6,2 & 8,0 & 9,0 & 6,9 & - \\
\hline
\end{tabular}

Letras minúsculas diferentes entre os quadrantes indicam diferença significativa $(P<0.05)$ pelo teste de Kruskal-Wallis. 0,05 de probabilidade. Clim - Aviário climatizado e Conv - Aviário convencional. TSMA - Temperatura superficial média das aves, ns - não significativo

Tabela 4. Comparação da temperatura, umidade relativa e velocidade do ar no momento da coleta das imagens termográficas

\begin{tabular}{|c|c|c|c|c|c|c|}
\hline \multirow{2}{*}{$\begin{array}{l}\text { Idade } \\
\text { (dias) }\end{array}$} & \multicolumn{2}{|c|}{ Temperatura do ar $\left({ }^{\circ} \mathrm{C}\right)$} & \multicolumn{2}{|c|}{ Umidade relativa (\%) } & \multicolumn{2}{|c|}{ Velocidade do ar $\left(\mathrm{m} \mathrm{s}^{-2}\right)$} \\
\hline & Clim. & Conv. & Clim. & Conv. & Clim. & Conv. \\
\hline 7 & $29,9 \pm 0,1$ & $31,8 \pm 0,1$ & $52,3 a \pm 0,4$ & $43,2 b \pm 0,2$ & $2,00 a \pm 0,09$ & $0,91 b \pm 0,12$ \\
\hline 14 & $25,3 \pm 0,2$ & $24,9 \pm 0,2$ & $63,1 \pm 0,4$ & $60,5 \pm 0,4$ & $1,68 a \pm 0,08$ & $0,16 b \pm 0,03$ \\
\hline 21 & $27,0 \pm 0,2$ & $26,1 \pm 0,1$ & $62,7 \pm 0,2$ & $62,7 \pm 0,2$ & $1,85 a \pm 0,07$ & $0,22 b \pm 0,02$ \\
\hline 28 & $28,7 \pm 0,1$ & $27,3 \pm 0,1$ & $62,3 \pm 2,0$ & $64,8 \pm 0,2$ & $2,01 \mathrm{a} \pm 0,06$ & $0,28 b \pm 0,02$ \\
\hline
\end{tabular}

*Diferença significativa pelo teste de t-Student a 0,05 de probabilidade. Clim - Aviário climatizado e Conv - Aviário convencional 
A.

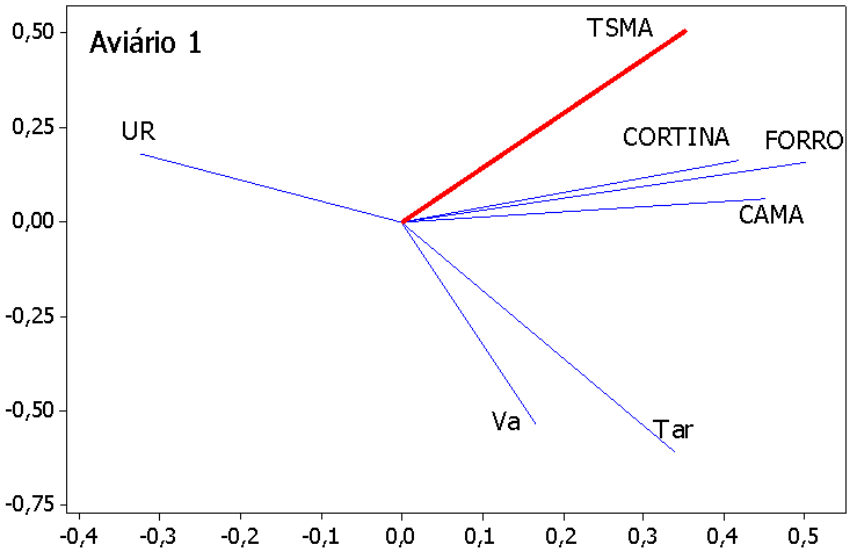

B.

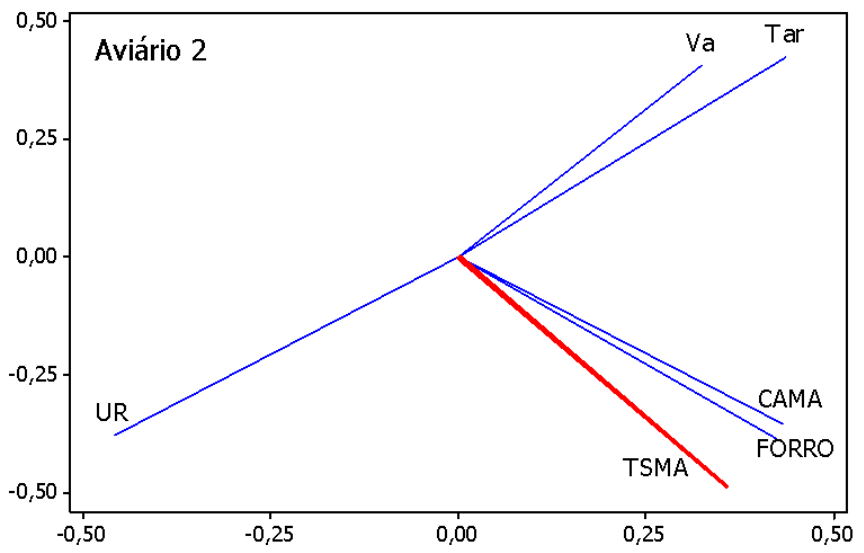

Figura 3. Gráfico de componentes principais da temperatura superficial das aves (TSMA), da temperatura superficial do forro, da temperatura superficial da cama (CAMA), da temperatura superficial da cortina, da temperatura do ar (Tar), da umidade relativa (UR) e da velocidade do ar (Va), para o aviário climatizado (A) e para o aviário convencional (B)

A correlação da temperatura do ar com a temperatura superficial das aves foi documentada em diversos estudos (Yahav et al., 2005; Dahlke et al., 2005; Welker et al., 2008) porém os resultados encontrados neste estudo indicam que esta associação é maior com as temperaturas superficiais da instalação; a associação entre as temperaturas superficiais da instalação e das aves confirma, por sua vez, a importância do uso de materiais de construção com baixa condutividade térmica que ajudam a manter o isolamento térmico das temperaturas externas e diminui a transferência de calor da instalação para os animais.

A transferência de calor sensível das aves foi significativamente maior $(\mathrm{p}<0,05)$ no aviário climatizado quando comparada com a do aviário convencional, pelo teste de t-Student a 0,05 de probabilidade; enfim, a velocidade do ar é maior e mais uniforme em aviários climatizados que contribuem com a também maior dissipação do calor por convecção nas aves (Tabela 5).

De acordo com Yahav et al. (2005) a velocidade do ar é o parâmetro que mais influencia a perda de calor sensível. É importante maximizar as trocas de calor sensível através
Tabela 5. Estimativa da perda de calor por convecção (Qc), radiação (Qr) e total (Qt) por idade das aves, utilizando-se dados da termografia

\begin{tabular}{ccrrr}
\hline \multirow{2}{*}{$\begin{array}{c}\text { Idade } \\
\text { (dia) }\end{array}$} & Aviário & \multicolumn{3}{c}{ Perda de calor $\left(\mathbf{w ~ ~ m ^ { - 2 } )}\right.$} \\
\cline { 3 - 5 } 7 & Clim. & Qc & \multicolumn{1}{c}{ Qr } & \multicolumn{1}{c}{ Qt } \\
& Conv. & $0,80 \mathrm{~A} \pm 0,4$ & $8.10-4 \pm 1.10-4$ & $2,20 \mathrm{~A} \pm 0,4$ \\
\multirow{2}{*}{14} & Clim. & $6,40 \mathrm{~A} \pm 1,1$ & $5.10-4 \pm 8.10-5$ & $0,86 \mathrm{~B} \pm 0,6$ \\
& Conv. & $2,10 \mathrm{~B} \pm 2,0$ & $2.10-3 \pm 3.10-4$ & $6,40 \mathrm{~A} \pm 1,1$ \\
21 & Clim. & $10,10 \mathrm{~A} \pm 1,1$ & $3.10-3 \pm 3.10-4$ & $2,10 \mathrm{~B} \pm 2,0$ \\
& Conv. & $4,60 \mathrm{~B} \pm 1,3$ & $3,5.10-3 \pm 2.10-4$ & $10,10 \mathrm{~A} \pm 1,1$ \\
\multirow{2}{*}{28} & Clim. & $6,70 \mathrm{~A} \pm 1,7$ & $2.10-3 \pm 50 \mathrm{~B} \pm 1,3$ \\
& Conv. & $4,40 \mathrm{~B} \pm 1,0$ & $2,8.10-3 \pm 5.10-4$ & $6,70 \mathrm{~A} \pm 1,7$ \\
\end{tabular}

Clim - Aviário climatizado e Conv - Aviário convencional; Letras maiúscula diferentes indicam diferença significativa pelo teste de t-Student a 0,05 de probabilidade

da diferença entre a temperatura superficial das aves e a temperatura do ar; quando esta diferença é mínima, as aves aumentam a transferência de calor por evaporação com auxílio da ofegação que tem custo energético elevado e queda do desempenho animal (Borges et al., 2003; Menegali et al., 2009).

\section{Conclusões}

1. Em condições de conforto térmico as temperaturas superficiais das aves são mais associadas com as temperaturas superficiais das instalações.

2. Nas condições experimentais deste trabalho o aviário com ventilação tipo túnel proporcionou a maior transferência de calor sensível pelas aves.

\section{Agradecimento}

Os autores agradecem ao Conselho Nacional de Desenvolvimento Científico e Tecnológico $(\mathrm{CNPq})$ pelo apoio financeiro a esta pesquisa.

\section{Literatura Citada}

Abreu, P. G.; Abreu, V. M. N.; Coldebella, A.; Jaenisch, F. R. F.; Paiva, D. P. Condições térmicas ambientais e desempenho das aves criadas em aviários com e sem o uso de forro. Arquivo Brasileiro de Medicina Veterinária e Zootecnia, v.59, p.1014-1020, 2007.

Aerts, M.; Wathes, C. M.; Berckmans, D. Dynamic databased modeling of heat production and growth of broiler chickens: development of an integrated management system. Biosystems Engineering, v.84, p.257-66, 2003.

Borges, S. A.; Maiorka, A.; Silva, A. V. F. Fisiologia do estresse calórico e a utilização de eletrólitos em frangos de corte. Ciência Rural, v.33, p.975-981, 2003.

Brecht, A. van; Hens, H.; Lemaire, J. L.; Aerts, J. M.; Degraeve, P.; Berckmans, D. Quantification of the heat exchange of chicken eggs. Poultry Science, v.84, p.353-361, 2005.

Curto, F. P. F.; Nääs, I. A.; Pereira, D. F.; Salgado, D. D. Estimativa do padrão de preferência térmica de matrizes pesadas (frangos de corte). Revista Brasileira de Engenharia Agrícola e Ambiental, v.11, p.211-216, 2007. 
Dahlke, F.; Gonzales, E.; Gadelha, A. C.; Maiorka, A.; Borges, S.A.; Rosa, P.S.; Faria Filho, D.E.; Furlan, R.L. Feathering, triodothyronine and thyroxine plasma levels and body temperature of two broiler lines raised under different temperatures. Ciência Rural, v.35, p.664-670, 2005.

Fiorelli, J.; Fonseca, R.; Morceli, J. A. B.; Dias, A. A. Influência de diferentes materiais de cobertura no conforto térmico de instalações para frangos de corte no oeste paulista. Engenharia Agrícola, v.30, p.986-992, 2010.

He, J.; Hoyano, A. Measurement and simulation of the thermal environment in the built space under a membrane structure. Building and Environment, v.44, p.1119-1127, 2009.

Menegali, I.; Tinôco, I. de F. F.; Baêta, F. C.; Cecon, P. R.; Guimarães, M. C. C; Cordeiro, M. B. Ambiente térmico e concentração de gases em instalações para frangos de corte no período de aquecimento. Revista Brasileira de Engenharia Agrícola e Ambiental, v.13, p.984-990, 2009.

Nascimento, G.R.; Nääs, I. A.; Pereira, D. F.; Baracho, M. S.; Garcia, R. Assessment of broilers surface temperature variation when exposed to different air temperature. Revista Brasileira de Ciência Avícola, v.13, p.259-263, 2011.
Santos, P. A.; Baêta, F. C; Tinôco, I. F. F; Albino, L. F. T.; Cecon, P. R. Ventilação em modos túnel e lateral em galpões avícolas e seus efeitos no conforto térmico, na qualidade do ar e no desempenho das aves. Revista CERES, v.56, p.172-180, 2009.

Silva, E.; Yanagi Júnior, T.; Braga Júnior, R.A.; Lopes, M.A.; Damasceno, F. A.; Silva, G. C. A. Desenvolvimento e validação de um modelo matemático para o cálculo da área superficial de frangos de corte. Engenharia Agrícola, v.29, p.1-7, 2009.

Tinôco, I. F. F. A granja de frangos de corte. In: Mendes, A. A.; Nããs, I. A.; Macari, M. (ed.) Produção de frangos de corte. Campinas: FACTA, 2004. p.55-84.

Welker, J. S.; Rosa, A. P.; Moura, D. J.; Machado, L. P.; Catelan, F; Uttpatel, R. Temperatura corporal de frangos de corte em diferentes sistemas de climatização. Revista Brasileira de Zootecnia, v.37, p.1463-1467, 2008.

Yahav, S.; Shinder, D.; Tanny, J.; Cohen, S. Sensible heat loss: the broiler's paradox. World's Poultry Science Journal, v.61, p.419-434, 2005.

Yahav, S.; Straschnow, A.; Luger, D.; Shinder, D.; Tanny, J.; Cohen, S. Ventilation, sensible heat loss, broiler energy, and water balance under harsh environmental conditions. Poultry Science, v.83, p.253-258, 2004. 